\title{
Prevalence of rotator cuff diseases in adults older than 40 years in or near Chuncheon city, Korea
}

\author{
Do-Young Kim, Jung-Taek Hwang, Sang-Soo Lee, Jun-Hyuck Lee, Min-Soo Cho \\ Department of Orthopedic Surgery, Chuncheon Sacred Heart Hospital, Hallym University College of Medicine, Chuncheon, Korea
}

\begin{abstract}
Background: To determine the prevalence of rotator cuff diseases in a population older than 40 years in or nearby Chuncheon city, Republic of Korea.

Methods: Sixty shoulders of 30 people older than 40 years who participated in a health lecture were examined for free by an orthopedic surgeon. Visual analog scale of pain and American Shoulder and Elbow Surgeons scores were assigned, and routine physical examination was performed. Ultrasonography was performed on the shoulder.

Results: On ultrasonographic examination, there were one shoulder with full thickness rotator cuff tear, 20 of 60 (33\%) with partial thickness rotator cuff tear, five of 60 (8\%) with calcific tendinitis, one of 60 (2\%) with tear of the long head of the biceps, and five of 60 (8\%) with tendinitis of the long head of the biceps. Participants older than 60 years showed significantly high proportions of lesion of the long head of the biceps and rotator cuff diseases $(\mathrm{P}=0.019$ and $\mathrm{P}=0.015$, respectively). Participants who performed physical labor had high proportions of rotator cuff tear and rotator cuff disease $(\mathrm{P}=0.001$ and $\mathrm{P}<0.001$, respectively).

Conclusions: Rotator cuff diseases showed a high prevalence in aged persons and resulted in a decrease in shoulder function.
\end{abstract}

Keywords: Aged person; Prevalence; Rotator cuff; Occupation; Ultrasonography

\section{INTRODUCTION}

Shoulder pain is the third most common musculoskeletal pain and is estimated to compose $16 \%$ of all cases of musculoskeletal pain in primary medical care [1,2]. There are 15 musculoskeletal pain cases per 1,000 primary medical care cases each year, totaling about $1 \%$ of all adults receiving primary medical care annually $[1,2]$. Patients who experience shoulder pain for more than 1 year compose $60 \%$ of all shoulder pain patients; if not treated, these patients will experience severe disabilities, poor quality of life, and loss of occupation [1,2].

Shoulder pain is defined as chronic when it has been present for more than 6 months, regardless of any treatment the patient has previously received. The most common medical cause of chronic shoulder pain is rotator cuff disease, which includes tendinosis of the rotator cuff or long head of the biceps, partial- or deep-thickness tear of the long head of the biceps tendon, and calcific tendinitis. Other medical causes of chronic shoulder pain include adhesive capsulitis, osteoarthritis of the arm and shoulder joints, instability of the arm and shoulder joints, and acro-

Received: June 1, 2020

Revised: July 24, 2020

Accepted: July 25, 2020

Correspondence to: Jung-Taek Hwang

Department of Orthopedic Surgery, Chuncheon Sacred Heart Hospital, Hallym University College of Medicine, 77 Sakju-ro, Chuncheon 24253, Korea Tel: +82-33-240-5197, Fax: +82-33-252-0177, E mail: drakehjt@hanmail.net, ORCID: https://orcid.org/0000-0003-4189-084X

Financial support: None.

Conflict of interest: None.

Copyright(C) 2020 Korean Shoulder and Elbow Society. All Rights Reserved.

This is an Open Access article distributed under the terms of the Creative Commons Attribution Non-Commercial License (http://creativecommons.org/licenses/by-nc/4.0/) which permits unrestricted non-commercial use, distribution, and reproduction in any medium, provided the original work is properly cited. 
mioclavicular joint disease [1].

Despite active studies that have been conducted overseas on the treatment and prevalence of shoulder pain [1-5], studies on the prevalence of shoulder pain and that of rotator cuff diseases that cause shoulder pain in Korea remain limited [6]. Accordingly, we examined 60 shoulder cases of 30 adults older than 40 years of age living in Chuncheon city, Korea and nearby areas to determine the prevalence of rotator cuff diseases that cause shoulder pain in this population.

\section{METHODS}

\section{Materials}

We conducted this study in compliance with the principles of the Declaration of Helsinki. The study's protocol was reviewed and approved by the Institutional Review Board of Chuncheon Sacred Heart Hospital (IRB No. 2020-04-011-003), and the need for informed consent was waived.

A total of 60 shoulder cases of 30 people over 40 years of age who participated in a health lecture held at the university hospital was included. The average age of study participants was $61.6 \pm 1.7$ years (range, $40-78$ years). Twelve patients were male and 18 were female. Seven patients resided in rural areas, while 23 resided in urban areas. Twenty-three were manual workers and seven were office workers. Sixteen complained of night pain (Table 1).

\section{Method}

For functional assessment of shoulder joints, the American Shoulder and Elbow Surgeons (ASES) scoring system established by the American Shoulder and Elbow Society in 1994 was deployed, and a physical examination was performed. Among 57 participants in the health lecture, 30 underwent ultrasound tests for both shoulder joints performed by an orthopedic specialist with 5 years of experience who focused on treating shoulder and

Table 1. Demographic data of the participants in this study

\begin{tabular}{lc}
\hline Variable & Value \\
\hline Total number & 30 \\
Sex (male:female) & $12: 18$ \\
Age (yr), mean \pm SD (range) & $61.6 \pm 1.7(40-78)$ \\
Age distribution $(<60: \geq 60)$ & $13: 17$ \\
Region (rural:urban) & $7: 23$ \\
Labor (physical:mental) & $23: 7$ \\
Dominance (right:left:both) & $24: 1: 4$ \\
Night pain & 16 \\
\hline
\end{tabular}

SD: standard deviation. elbow joints. Additionally, the 30 study participants also underwent score assessment and physical examination performed by two orthopedic nurses with 7 years of experience.

Participants who reported pain during the examination for presence of shoulder joint pain were asked further about the presence and extent of night pains, medical history of analgesics, and location of pain. A visual analog scale (VAS) was used to score the severity of pain, ranging from 0 points for no pain to 10 points for the most severe pain. Ultrasound tests have been used to identify tendinitis or tear of the long head of the biceps tendon, partial- or full-thickness tears of the rotator cuff, and rotator cuff diseases including calcific tendinitis.

Diagnosis of full-thickness tear of the rotator cuff was performed in accordance with the criteria as follows (Fig. 1) [7]: (1) the supraspinatus is not visible due to retraction of torn supraspinatus below the acromioclavicular joint; (2) loss or discontinuity in the local rotator cuff muscle accompanied by continual loss of normal anterior arch in the subdeltoid bursa; (3) loss of normal supraspinatus muscle parenchyma accompanied by increased distance between the supraspinatus and long head of the biceps tendon and exposure of the bare area of the bone and cartilage; (4) hypoechoic or anechoic extension observed through the full parenchyma of the rotator cuff; (5) fluid in the subacromial and subdeltoid bursa with or without fluid in the sheath of the long head of the biceps tendon.

Partial-thickness tear of the rotator cuff was diagnosed by a local hypoechoic or anechoic defect of the bursa or a joint near the rotator cuff in two perpendicular planes (Fig. 2) [8]. Calcification of the rotator cuff appears as a hyperechoic lesion on ultrasound imaging (Fig. 3). Depending on the amount and stage of calcifi-

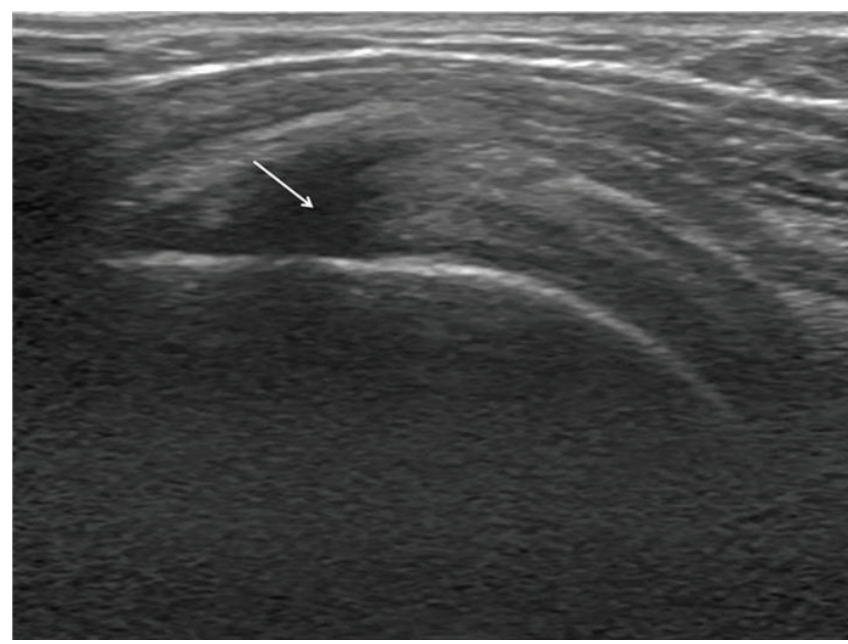

Fig. 1. Sonographic finding of the full-thickness rotator cuff tear. The arrow indicates the full-thickness rotator cuff tear. 
cation, the type of lesion can appear clear with acoustic shadowing or could be blurry or a type with no shadowing $[9,10]$.

In the transverse sonographic view, tenosynovitis of the long head of the biceps tendon appears like a fried egg due to a halo effect of hypoechoic effusion near the dense shadow of the long head of the biceps tendon (Fig. 4) [11]. A partial-thickness tear could appear as a crevice (Fig. 5), while a full-thickness tear may not be visible because of an involution. Rupture is often accompanied by medial dislocation of the long head of the biceps tendon [12].

\section{Statistical Analysis}

The Mann-Whitney U-test was used to compare the measured mean values, and a statistical analysis was performed using the

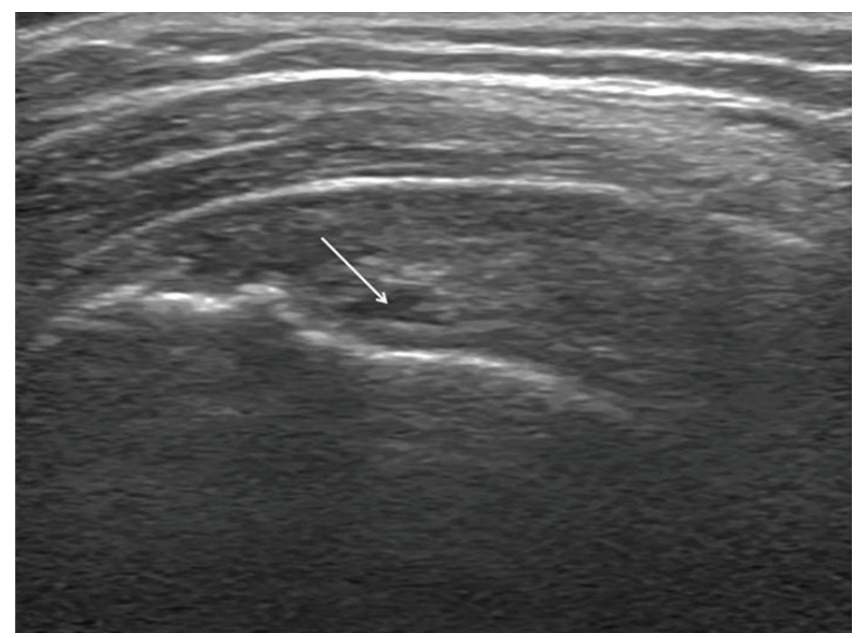

Fig. 2. Sonographic finding of the partial-thickness rotator cuff tear. The arrow indicates the partial-thickness rotator cuff tear.

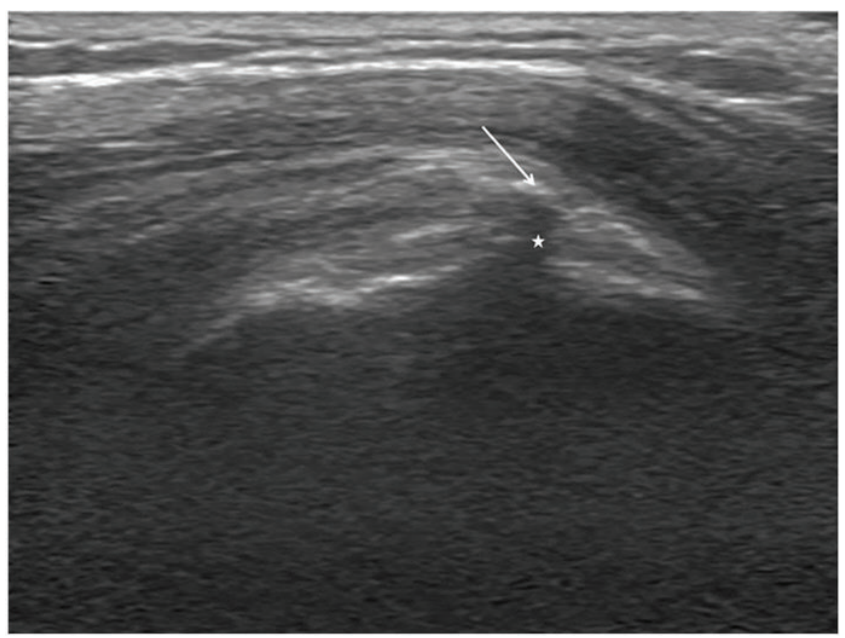

Fig. 3. Sonographic finding of calcific tendinitis of the rotator cuff. The arrow indicates a calcific deposit of the rotator cuff. The asterisk indicates acoustic shadowing.
SPSS ver. 13.0 (SPSS Inc., Chicago, IL, USA), with statistical significance established at $\mathrm{P}<0.05$.

\section{RESULTS}

Of the 60 shoulder cases, 39 were painful, with 15 experiencing moderate degree of pain with a VAS score of 4 points or higher. The average VAS and ASES scores were $2.2 \pm 0.3(0-8)$ points and $80.2 \pm 2.1$ (35-100) points, respectively. During ultrasound examination, one shoulder showed a full-thickness rotator cuff tear, 20 of 60 (33\%) showed a partial-thickness rotator cuff tear, five of 60 (8\%) presented with calcific tendinitis, one of 60 (2\%) demonstrat-

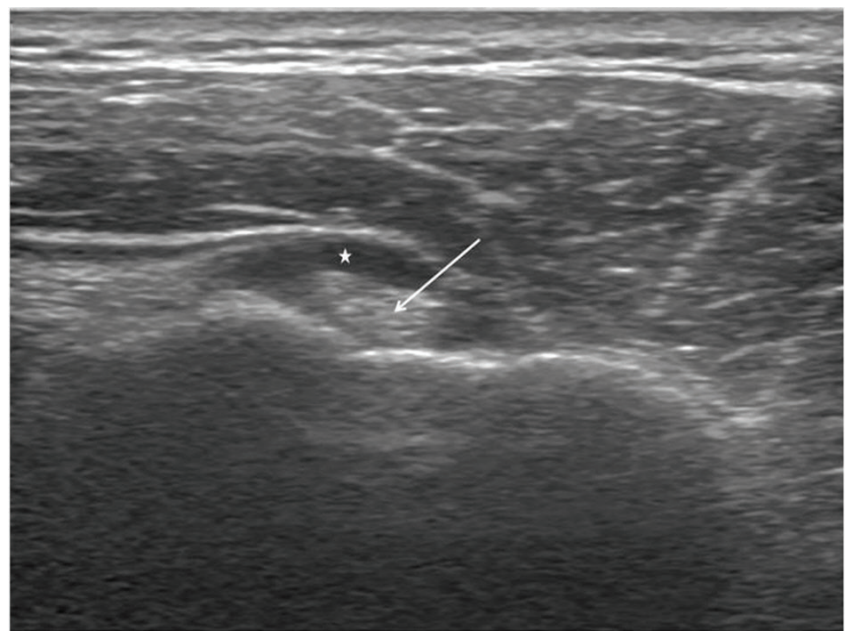

Fig. 4. Sonographic finding of long head of the biceps tendinitis. The arrow indicates the long head of the biceps tendon. The asterisk indicates effusion surrounding the long head of the biceps tendon. The shape is similar to that of a fried egg.

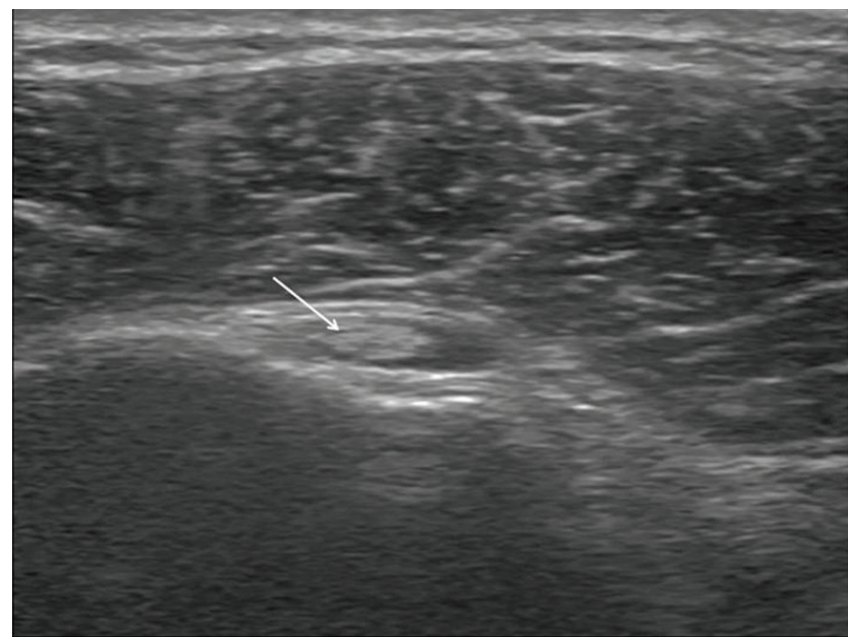

Fig. 5. Sonographic finding of a long head of the biceps tendon partial-thickness tear. The arrow indicates a small cleft on the long head of the biceps tendon. 
ed a tear of the long head of the biceps tendon, and five of 60 (8\%) presented tendinitis of the long head of the biceps tendon (Table 2). Of the participants aged 60 years or older, the rate of rotator cuff rupture, long head of the biceps tendon lesion, and rotator diseases was significantly higher $(\mathrm{P}=0.006, \mathrm{P}=0.025$, and $\mathrm{P}=0.006$, respectively) than those of younger participants (Table 3). Significantly high rates among manual workers were found regarding rotator cuff rupture and rotator cuff disease $(\mathrm{P}=0.002$ and $\mathrm{P}<0.001$, respectively). Meanwhile, significantly low ASES scores were observed among manual workers' shoulders $(\mathrm{P}=0.025)$ (Table 4). In addition, VAS and ASES scores were significantly lower in shoulders presenting rotator cuff rupture $(\mathrm{P}<0.001$ and $\mathrm{P}=0.004)$. Lower ASES scores were noted in shoulders with long head of the biceps tendon lesion $(\mathrm{P}=0.032)$. The VAS and ASES scores were significantly lower among those with rotator cuff disease relative to those without rotator cuff disease $(\mathrm{P}<0.001$ and $\mathrm{P}<0.001)$ (Table 5).

\section{DISCUSSION}

The majority of patients in Korea who experience shoulder pain postpone visiting the hospital until no effect is achieved with a variety of conservative treatments such as physical therapy or acupuncture or significant dysfunction or severe pain is experienced. Because of this, it is difficult to identify and treat the cause of the pain early [6]. In this research, among 60 shoulder cases, 39 (65\%) were painful and 15 (25\%) experienced a moderate degree of pain with a VAS score of four points or higher. There is a difference in the distribution of causal diseases of shoulder pain by age. In patients younger than 40 years, shoulder instability or mild rotator cuff disease (i.e., impingement syndrome or tendinosis) is the most common cause, while, in patients older than 40 years of age, risk of developed chronic rotator cuff disease (partial or deep tear), adhesive arthritis, or glenohumeral osteoarthritis increases [1,2,13].

Manual occupations and leisure activities show correlations

Table 2. The rotator cuff diseases of the 60 shoulders of the participants in this study

\begin{tabular}{lc}
\hline Pathology & No. $(\%)$ \\
\hline Partial thickness rotator cuff tear & $20(33)$ \\
Full thickness rotator cuff tear & $1(2)$ \\
Calcific tendinitis of rotator cuff & $5(8)$ \\
LHB tendinitis & $5(8)$ \\
LHB tear & $1(2)$ \\
\hline
\end{tabular}

LHB: long head of biceps.

Table 3. The correlation between age and rotator cuff diseases

\begin{tabular}{lccc}
\hline Variable & Age $<60 \mathrm{yr}$ & Age $\geq 60 \mathrm{yr}$ & P-value \\
\hline RC tear & 4 & 17 & 0.006 \\
Calcific tendinitis of RC & 2 & 3 & 0.876 \\
LHB disease $^{\star}$ & 0 & 6 & 0.025 \\
$\mathrm{RCD}^{\dagger}$ & 6 & 20 & 0.006 \\
\hline
\end{tabular}

RC: rotator cuff, LHB: long head of biceps, RCD: rotator cuff disease. ${ }^{*}$ LHB disease: $\mathrm{LHB}$ tendinitis and LHB tear; ${ }^{\dagger}$ Rotator cuff tear, LHB disease, calcific tendinitis of RC.

Table 4. The correlation between the type of labor and functional scores with pathology

\begin{tabular}{lccc}
\hline Variable & Physical labor & Mental labor & P-value \\
\hline VAS, mean \pm SD & $2.5 \pm 2.3$ & $1.3 \pm 1.6$ & 0.089 \\
ASES score, mean \pm SD & $77.6 \pm 17.1$ & $89.0 \pm 11.5$ & 0.025 \\
RC tear & 21 & 0 & 0.002 \\
Calcific tendinitis of RC & 5 & 0 & 0.201 \\
LHB disease & 6 & 0 & 0.158 \\
RCD $^{\dagger}$ & 26 & 0 & $<0.001$ \\
\hline
\end{tabular}

VAS: visual analog scale, ASES: American Shoulder and Elbow Surgeons, RC: rotator cuff, LHB: long head of biceps, RCD: rotator cuff disease. ${ }^{*} \mathrm{LHB}$ disease: LHB tendinitis and LHB tear; ${ }^{\dagger}$ Rotator cuff tear, LHB disease, calcific tendinitis of RC.

Table 5. The correlation between the pathologies and functional scores

\begin{tabular}{lccccccccc}
\hline Variable & RC tear & No RC tear & P-value & LHB disease & No LHB disease & P-value & RCD $^{\dagger}$ & No RCD & P-value \\
\hline VAS & $3.6 \pm 2.0$ & $1.5 \pm 1.9$ & $<0.001$ & $3.0 \pm 1.8$ & $2.1 \pm 2.2$ & 0.177 & $3.5 \pm 2.1$ & $1.2 \pm 1.8$ & $<0.001$ \\
ASES score & $71.6 \pm 14.8$ & $84.9 \pm 15.8$ & 0.004 & $69.7 \pm 9.9$ & $81.4 \pm 16.9$ & 0.032 & $70.4 \pm 15.2$ & $87.7 \pm 13.7$ & $<0.001$ \\
\hline
\end{tabular}

Values are presented as mean \pm standard deviation.

RC: rotator cuff, LHB: long head of biceps, RCD: rotator cuff disease, VAS: visual analog scale, ASES: American Shoulder and Elbow Surgeons.

${ }^{*} \mathrm{LHB}$ disease: $\mathrm{LHB}$ tendinitis and LHB tear; ${ }^{\dagger}$ Rotator cuff tear, LHB disease, calcific tendinitis of RC. 
with shoulder pain. Sports with frequent collisions or activities like lifting of heavy materials can trigger shoulder instability or osteoarthritis in acromioclavicular joints, and upward movement of arms in activities or sports may result in a morbid condition of the rotator cuff $[1,13]$. This research reported significantly higher rates of rotator cuff rupture and rotator cuff disease in manual workers compared to office workers $(\mathrm{P}=0.002$ and $\mathrm{P}<0.001$, respectively).

Previous treatments that aggravate or alleviate pain or causative factors could be clues in attempting to diagnose rotator cuff disease. Night pain that comes on after sleeping on the injured shoulder or a trauma history may be related to rupture of the rotator cuff. A painful arc induced by lifting activities involving the arm is not only related to rotator cuff rupture, but also to tendinosis. Past history of shoulder surgery is important because of early and late complications that may appear such as adhesive arthritis and glenohumeral osteoarthritis $[1,13]$.

Hermans et al. [14] reported that the incidence of rotator cuff disease including tendinosis and rupture was 33\% to $81 \%$ in their five studies performed using magnetic resonance imaging or ultrasound. In addition, Tashjian [15] observed deep-thickness rotator tear at a rate of $25 \%$ among those in their 60 s and at a rate of $80 \%$ among those in their 80 s using magnetic resonance imaging or ultrasound. In this study, there was one patient $(1 / 60,2 \%)$ with a full-thickness rotator cuff tear; 20 patients (20/60, 33\%) with partial-thickness rotator cuff tear; and a significantly high ratio of rotator cuff rupture, long head of the biceps tendon lesions, and rotator cuff disease in those aged 60 years and older ( $\mathrm{P}=0.006, \mathrm{P}=0.025, \mathrm{P}=0.006$, respectively).

Oliva et al. [16] reported the prevalence of calcific tendinitis of the rotator cuff as $2.7 \%$ to $22 \%$ and that it was especially prevalent in women aged 30 to 35 years. In this research, five of 60 (8\%) cases of calcific tendinitis were observed. Murthi et al. [17] reported that, of more than 200 shoulders that underwent arthroscopic subacromial decompression surgery for impingement syndrome, 80 (40\%) showed degenerative change of the long head of the biceps tendon. Beall et al. [18] reported that, among 111 patients who underwent arthroscopic or open surgery for shoulder pain, 23 (23\%) showed partial- or deep-thickness rupture of the long head of the biceps tendon. In this research, five patients $(5 / 60 ; 8 \%)$ showed tendinitis of the long head of the biceps tendon, and one patient $(1 / 60,2 \%)$ showed a tear of the long head of the biceps lesion.

Rotator cuff diseases of the shoulder appear with a high prevalence in elderly people and result in a decrease in shoulder function. Also, manual laborers more often experience rotator cuff disease than do office workers. Therefore, exploring more pre- ventive and therapeutic considerations is thought to be appropriate in particular for old-aged manual laborers.

\section{ACKNOWLEDGMENTS}

We would like to express sincere gratitude to two clinical research nurses, Byeong-Yi Choi and Ok-Hwa Park, for helping with measurement of participant visual analog scale and American Shoulder and Elbow Surgeons scores and with the ultrasound tests. We also am grateful to specialist Byung-Chan Kwak, who helped with data organization.

\section{ORCID}

Do-Young Kim

Jung-Taek Hwang

Sang-Soo Lee

Jun-Hyuck Lee

Min-Soo Cho https://orcid.org/0000-0003-3735-1640

https://orcid.org/0000-0003-4189-084X

https://orcid.org/0000-0001-5074-7581

https://orcid.org/0000-0002-8153-2919

https://orcid.org/0000-0002-9282-6533

\section{REFERENCES}

1. Burbank KM, Stevenson JH, Czarnecki GR, Dorfman J. Chronic shoulder pain: part I: evaluation and diagnosis. Am Fam Physician 2008;77:453-60.

2. House J, Mooradian A. Evaluation and management of shoulder pain in primary care clinics. South Med J 2010;103:1129-35

3. Andersson HI, Ejlertsson G, Leden I, Rosenberg C. Chronic pain in a geographically defined general population: studies of differences in age, gender, social class, and pain localization. Clin J Pain 1993;9:174-82.

4. Chard MD, Hazleman R, Hazleman BL, King RH, Reiss BB. Shoulder disorders in the elderly: a community survey. Arthritis Rheum 1991;34:766-9.

5. Hasvold T, Johnsen R. Headache and neck or shoulder pain: frequent and disabling complaints in the general population. Scand J Prim Health Care 1993;11:219-24.

6. Lee JY, Park JY, Won JH, Lim ST, Park HG, Yoo MJ. The prevalence of shoulder pain in adults over 40 years old in rural area of chonan city. J Korean Orthop Assoc 2002;37:374-8.

7. Bianchi S, Martinoli C, Abdelwahab IF. Ultrasound of tendon tears. Part 1: general considerations and upper extremity. Skeletal Radiol 2005;34:500-12.

8. Yen CH, Chiou HJ, Chou YH, et al. Six surgery-correlated sonographic signs for rotator cuff tears: emphasis on partial-thickness tear. Clin Imaging 2004;28:69-76.

9. Saboeiro GR. Sonography in the treatment of calcific tendinitis 
of the rotator cuff. J Ultrasound Med 2012;31:1513-8.

10. Chiou HJ, Chou YH, Wu JJ, Hsu CC, Huang DY, Chang CY. Evaluation of calcific tendonitis of the rotator cuff: role of color Doppler ultrasonography. J Ultrasound Med 2002;21:289-95.

11. Pfahler M, Branner S, Refior HJ. The role of the bicipital groove in tendopathy of the long biceps tendon. J Shoulder Elbow Surg 1999;8:419-24.

12. Skendzel JG, Jacobson JA, Carpenter JE, Miller BS. Long head of biceps brachii tendon evaluation: accuracy of preoperative ultrasound. AJR Am J Roentgenol 2011;197:942-8.

13. Mitchell C, Adebajo A, Hay E, Carr A. Shoulder pain: diagnosis and management in primary care. BMJ 2005;331:1124-8.

14. Hermans J, Luime JJ, Meuffels DE, Reijman M, Simel DL, Bierma-Zeinstra SM. Does this patient with shoulder pain have ro- tator cuff disease? The rational clinical examination systematic review. JAMA 2013;310:837-47.

15. Tashjian RZ. Epidemiology, natural history, and indications for treatment of rotator cuff tears. Clin Sports Med 2012;31:589604.

16. Oliva F, Via AG, Maffulli N. Calcific tendinopathy of the rotator cuff tendons. Sports Med Arthrosc Rev 2011;19:237-43.

17. Murthi AM, Vosburgh CL, Neviaser TJ. The incidence of pathologic changes of the long head of the biceps tendon. J Shoulder Elbow Surg 2000;9:382-5.

18. Beall DP, Williamson EE, Ly JQ, et al. Association of biceps tendon tears with rotator cuff abnormalities: degree of correlation with tears of the anterior and superior portions of the rotator cuff. AJR Am J Roentgenol 2003;180:633-9. 